\title{
REBELS
}

NEW AMERICANISTS

A series edited by Donald E. Pease 
2000028088

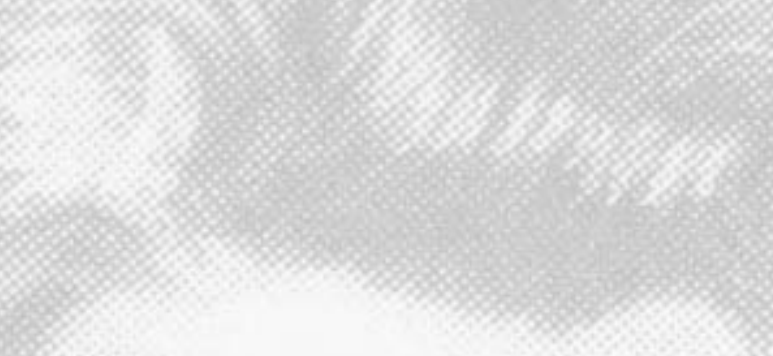

Cose88:
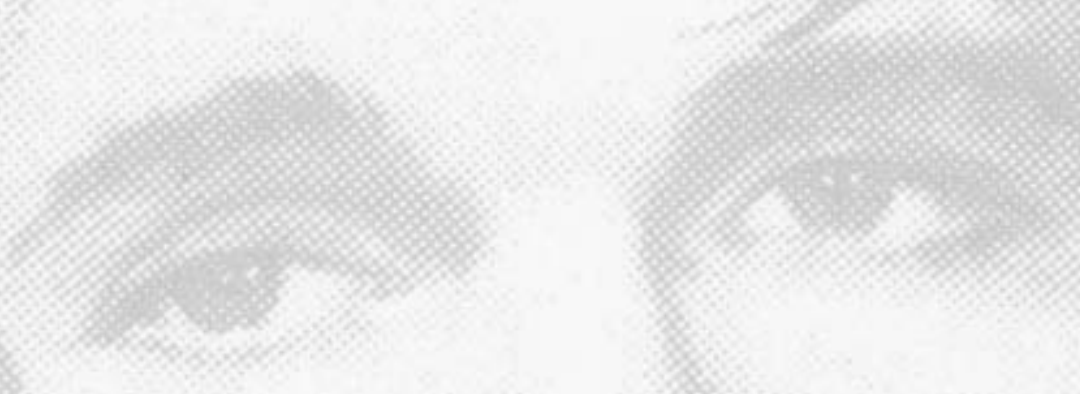


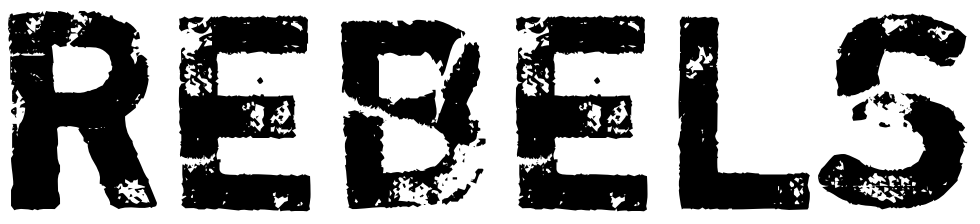

YOUTH AND THE COLD WAR ORIGINS OF IDENTITY

\section{LEEROM MEDOVOI}


(C) 2005 DUKE UNIVERSITY PRESS

All rights reserved

Printed in the United States

of America on acid-free paper

Designed by Amy Ruth Buchanan

Typeset in Scala with Shortcut display

by Tseng Information Systems, Inc.

Library of Congress Cataloging-

in-Publication Data appear on the

last printed page of this book. 